\title{
Role of Antibody Anti-AGE on the Expression of Nephrin and Rage in Primary Glomerulus Cell Culture Exposed to AGE
}

\author{
Rudy Salam ${ }^{1 *}$, Diana Lyrawati , Nursamsu ${ }^{2}$
}

\author{
${ }^{1}$ Department of Pharmacy, Faculty of Medicine, University of Brawijaya, Malang, Indonesia \\ ${ }^{2}$ Division of Nephrology and Hypertension, Department of Internal Medicine, Dr. Saiful Anwar Public Hospital, Malang, Indonesia
}

\section{ABSTRACT}

Nephrin is associated with the initial stage of the loss of the permeability barrier in diabetic nephropathy. Interaction AGE-RAGE in creases angiotensin II on Renin Angiotensin-Aldosterone System (RAAS) and activation of protein kinase c (PKC) which induce al terations in nephrin mRNA expression. Alterations of nephrin expression induce transformation of slit membrane structure and the permeability changes at the glomerular filtration barrier. Anti-AGE vaccination once may cause the changes of nephrin and RAGE expression and can prevent progression of diabetic nephropathy. This study used primary glomerulus cell culture obtained from renal of Wistar rat aged 3 months, weighing 200-300 grams and assigned into negative control group that exposed to BSA $100 \mu \mathrm{g} / \mathrm{mL}$, pos itive control group that exposed to AGE-BSA $100 \mu \mathrm{g} / \mathrm{mL}$, treatment group 1 that exposed to polyclonal anti-AGE antibody $5 \mu \mathrm{g} / \mathrm{mL}$ and AGE-BSA $100 \mu \mathrm{g} / \mathrm{mL}$ and treatment group 2 that exposed to monoclonal anti-CML antibody $5 \mu \mathrm{g} / \mathrm{mL}$ and AGE-BSA 100 $\mu \mathrm{g} / \mathrm{mL}$. Paired t-test with a 0.05 level of confidence results showed that there were significantly different $\mathrm{v}$ in level of RAGE expres sion between experimental groups with control groups. Administration of polyclonal anti-AGE antibody decreased RAGE expression compared to negative control $(\mathrm{p}=0.188)$ and positive control $(\mathrm{p}=0.000)$. RAGE expression did not differ significantly in administra tion of monoclonal anti-CML antibody compared to negative control but significant with positive control. Administration of monoclonal anti-CML antibody inhibited increasing of nephrin expression compared to negative and positive control $(p=0.73 ; 0.125)$. In conclusion, this study suggested that administration of polyclonal anti-AGE or monoclonal anti-CML antibody could inhibit increasing of RAGE and nephrin expression in glomerulus primary culture that exposed to AGE which is expected to prevent the progression of diabetic nephropathy.

Keywords: Anti-AGE antibody, $A G E, R A G E$, nephrin, primary glomerulus cell culture

\section{INTRODUCTION}

Diabetic nephropathy is one of diabetic mellitus complication leading to thickening of glomerular basal membrane, glomerular hypertrophy and mesangial expansion [1]. The pathogenesis of diabetic nephropathy involve various mechanism and include hyperglycaemic condition, polyol pathway activation, renin-angiotensin system, reactive oxygen species (ROS), activation of protein kinase $\mathrm{C}$ (PKC) pathway, increase of advanced glycation end-product (AGE) and glomerular hyperfiltration $[1,2]$. Interaction of extracellular AGE with Receptor for Advanced Glycation End Products (RAGE) increases angiotensin II on Renin Angiotensin-Aldosterone System (RAAS) and activation of protein kinase

${ }^{*}$ Corresponding author:

Rudy Salam

Department of Biomedicine, Faculty of Medicine,

Brawijaya University,

Jalan Veteran, Malang, Indonesia 65145

E-mail: rudy_salam@ub.ac.id c (PKC) which induce alterations in nephrin mRNA expression $[3,4]$.

Nephrin is required for renal development process for podocyte maturation and formation of SD [5]. Downregulation of nephrin expression occurred on glomerular disease condition. Interestingly, upregulation of nephrin expression has been reported at early stage of glomerular injury and decreased at late stages of nephropathy (follow-up period up to 6 months using STZ model) [1]. Activation of PKC causes substantial increase of nephrin mRNA and protein expression [6].

Blocking AGE by amino guanidine, pyridoxamine, alagebrium and monoclonal antibody anti-TGF- $\beta$ con-

\section{How to cite:}

Salam R, Lyrawati D, Nursamsu (2017) Role of Antibody AntiAge on the Expression of Nephrin and Rage in Primary Glomerulus Cell Culture Exposed to Age. J. Trop. Life. Science 7 (1): 102-107. 
tinuously could protect diabetic patients from glomerulosclerosis and renal failure [7, 8]. Such treatment is costly if applied lifetime to manage diabetic vascular complications. Anti-AGE vaccination once may inhibit diabetic complication progression. AGE consist of glycation protein antigenic properties which could be used to develop antibody [9]. Administration of human RAGE antibody increases survival and cytoskeleton dynamicity of podocyte [10]. Anti-AGE antibody induces formation of immune complex with AGE. The correlation of decreasing AGE level with increasing of immune complex in vascular circulation indicate the role of anti-AGE antibody in decreasing of AGE level by inhibits signalling activation of factors that causes DN [11]. However, the role of antibody anti-AGE in nephrin and RAGE expression is still unclear whether upregulation or downregulation. The aims of this study were to examine the effects of anti-AGE antibody on RAGE and nephrin expression on primary glomerulus cells culture after incubated with AGE.

\section{MATERIALS AND METHODS}

\section{Primary glomeruli cell culture}

Primary glomeruli cell culture obtained from renal of Wistar rat aged 3 months, weighing 200-300 grams from Laboratory Bioscience University of Brawijaya. Antibody anti-AGE used Anti-Carboxymethyl Lysine/ Anti-CML (Circulex, cy-m1028) and polyclonal antibody anti-AGE (Abcam, ab23732). Antibody for RAGE used monoclonal antibody anti-RAGE (Circulex, cym1038) and nephrin used monoclonal antibody antinephrin (Bioss, bs-0513r).

Kidney male Wistar rat at ages 3 months (Laboratory Bioscience University of Brawijaya) were dissected and cut into small pieces (1-2 mm cubes) with a surgical blade in PBS solution. The tissues were digested in collagenase solution containing $1 \mathrm{mg} / \mathrm{mL}$ collagenase A (Roche Diagnostics GmbH, Mannheim, Germany) and $0.2 \mathrm{mg} / \mathrm{mL}$ deoxyribonuclease I (Roche Diagnostics $\mathrm{GmbH})$ in Hanks' Balanced Salt Solution at $37^{\circ} \mathrm{C}$ for $60 \mathrm{~min}$. The collagenase-digested tissues were gently pressed through a $100 \mathrm{~mm}$ cell strainer (BD Biosciences, Stockholm, Sweden) using a flattened pestle. Digested tissues was sentrifugated with $800 \mathrm{rpm}$ for 4 min. Supernatant was removed out and collected pellet was resuspended using deionized water.

Resuspended pellet were cultured in culture dishes or glass coverslips (Asahi techno glass, Tokyo, Japan) using RPMI $1 \times$ medium that's containing $5 \%$ fetal bovine serum (Cansera International, Canada) supplemented with $1 \%$ Insulin-Transferrin-Selenium-A, liq- uid media supplement (Invitrogen), $100 \mathrm{U} / \mathrm{ml}$ penicillin, and $100 \mathrm{mg} / \mathrm{mL}$ streptomycin. Cultures were incubated in a $37^{\circ} \mathrm{C}$ humidified incubator with $5 \% \mathrm{CO}_{2}$.

\section{Treatment monoclonal antibody Anti-CML and poly- clonal antibody Anti-AGE}

Primary glomerulus cells incubated for 48 hours and they were divided into 4 groups. Group 1 were treated with polyclonal anti-AGE antibody $5 \mu \mathrm{g} / \mathrm{mL}$ and AGE-BSA $100 \mu \mathrm{g} / \mathrm{mL}$. Group 2 were treated with monoclonal anti-CML antibody $5 \mu \mathrm{g} / \mathrm{mL}$ and AGEBSA $100 \mu \mathrm{g} / \mathrm{mL}$. For negative control, cells at group 3 were treated with BSA $100 \mu \mathrm{g} / \mathrm{mL}$ and AGE-BSA 100 $\mu \mathrm{g} / \mathrm{mL}$ for positive control group. Group 1 and group 2 were incubated for 30 minutes after the administration of antibody, followed by administration of AGEBSA then incubated for 24 hours. Negative control was incubated for 24 hours after the administration of BSA and positive control incubated for 24 hours after administration of AGE-BSA. Analysis of nephrin and RAGE expression was performed after 24 hours treatment.

\section{Immunofluorescence microscopy}

After treatment, primary glomeruli cells culture was fixed in $2 \%$ paraformaldehyde in PBS for 10 minutes, permeabilized with $0.3 \%$ Triton X-100 in PBS for 2 minutes, and stained with antibodies. Rabbit antinephrin mouse and mouse anti-RAGE antibody was applied as primary antibodies for double labelling. After washing with PBS, the specimens were stained with Goat anti-rabbit IgG-FITC (Santa Cruz; sc-2012) and Rabbit anti-mouse IgG-R (Santa Cruz; sc-2092), rewashed with PBS, and subsequently reacted. Immunofluorescences of the specimens were observed with a laser scanning confocal microscope (MRC-1024; Bio-Rad Laboratories). Visualization of expression of nephrin and RAGE was performed on three fields of view of each slide. Fluorescent density of nephrin and RAGE were measured using image J version 1.49.

\section{Statistical analysis}

All data were analysed by SPSS 20.0 software and expressed as mean \pm standard deviation (SD). The significance of difference was determined by paired t-test. A value of $p>0.05$ was considered statistically significant.

\section{RESULTS AND DISCUSSION}

Average values of RAGE expression in negative and positive control groups were $262,923.50 \pm 29,997.98$ 
Table 1. Results of paired t-test analysis of RAGE expression among control groups and treatment groups

\begin{tabular}{lcc}
\hline \multicolumn{1}{c}{ Groups } & $t$ value & $\begin{array}{c}\text { Significance } \\
(\alpha)\end{array}$ \\
\hline Negative control - positive control & -43.55 & 0.000 \\
Negative control - polyclonal treatment & -1.52 & 0.188 \\
Negative control - monoclonal treatment & -3.08 & 0.027 \\
Positive control - polyclonal treatment & 8.79 & 0.000 \\
Positive control - monoclonal treatment & 2.17 & 0.082 \\
Polyclonal treatment - monoclonal & -1.87 & 0.121 \\
treatment & & \\
\hline
\end{tabular}

Table 2. Results of paired t-test analysis of nephrin expression among control groups and treatment groups

\begin{tabular}{|c|c|c|}
\hline Groups & $t$ value & $\begin{array}{l}\text { Significance } \\
\qquad(\alpha)\end{array}$ \\
\hline Negative control - positive control & 13.59 & 0.000 \\
\hline Negative control - polyclonal treatment & 2.14 & 0.086 \\
\hline Negative control - monoclonal treatment & 2.27 & 0.073 \\
\hline Positive control - polyclonal treatment & 11.21 & 0.000 \\
\hline Positive control - monoclonal treatment & 1.84 & 0.125 \\
\hline $\begin{array}{l}\text { Polyclonal treatment - monoclonal treat- } \\
\text { ment }\end{array}$ & 2.68 & 0.044 \\
\hline
\end{tabular}

and $942,532.33 \pm 19,081.42 ; 363,53 \pm 158,126.25$. RAGE expression on experimental groups after treated by AGE continued with antibody polyclonal and monoclonal were $363,528.67 \pm 158,126.25$ and $654,396.83 \pm$ $325,322.83$.

Table 1 showed the results of paired t-test of treatment groups with control groups with a 0.05 level of confidence and the results showed that there were significant differences in level of RAGE expression. Administration of polyclonal antibody decreased RAGE expression among negative control $(\mathrm{p}=0.188)$ but not in positive control $(\mathrm{p}=0.000)$. In contrast to monoclonal anti-AGE antibody, RAGE expression had no different significantly compared to negative control but significant than positive control. This result indicated that antibody anti-AGE blocked expression of RAGE.

Nephrin expressions in negative control group were $284,514.67 \pm 52,644.92$ and $615,802.00 \pm 10,390.73$ for positive control group. Average values of nephrin expressions in polyclonal anti-AGE and monoclonal antiCML antibody treatment groups were $205544.00 \pm$ $86,150.45$ and $451,740.17 \pm 214,140$. Completely paired t-test of nephrin expression results showed in Table 2. Administration of monoclonal anti-AGE antibody in- hibited decreasing of nephrin expression compared to negative and positive control ( $\mathrm{p}=0.73 ; 0.125)$. Nephrin expressions in polyclonal anti-AGE antibody treatment groups were significantly different compared to negative control groups $(\mathrm{p}<0.05)$ in contrast with positive control. This result showed that nephrin expressions inhibited by administration of polyclonal anti-AGE or monoclonal anti-CML antibody.

The role of antibody anti-AGE in nephrin and RAGE expression is still unclear whether increasing or decreasing. To examine the effects of anti-AGE antibody treatment on RAGE and nephrin expression on primary glomerulus cells culture, we exposed cultured glomerulus primary cells with anti-AGE antibody and AGE. In normal condition, podocytes and glomerular endothelial cells, among other renal cell types express RAGE [12]. Interaction of AGE-RAGE induce the activation of inflammatory signalling [10]. Signalling pathways which activated by AGE-RAGE are ERK (extracellular signal-regulated kinase)1/2, p38 MAPK (mitogen-activated-protein-kinase)-JNK (c-Jun N-terminal kinases), JAK (Janus-kinase)-STAT (signal transducer and activator of transcription), and Rac-Cdc42 [12]. Activation of inflammatory signalling pathways increasing of reactive oxygen species (ROS) and leads positive feed-forward loop of NF-KB activation which is induces RAGE expression [12]. In this study, we hypothesized that anti-AGE antibody inhibits RAGE expression. Indeed, it had been demonstrated in administration of polyclonal antibody decreased RAGE expression among negative control $(p=0.188)$ but not in positive control $(\mathrm{p}=0.000)$. In contrast to monoclonal anti-AGE antibody, RAGE expression did not differ significantly compared to negative control but significant than positive control. This result indicated that both of polyclonal and monoclonal anti-AGE antibody could inhibit RAGE expressions. The possibility of mechanisms that are involved in inhibition of RAGE expression is polyclonal and monoclonal anti-AGE antibody inhibit interaction of AGE-RAGE that cause inhibition of NF-KB activation and other signalling pathways and leads to inhibition of RAGE expression [12].

Nephrin is recently found in podocyte and required to kidney development process for maturation of podocyte cells, formation of slit diaphragm (SD) complex and maintenance of glomerular filtration barrier $[1,5]$. Downregulation of nephrin expression occurred at glomerulus disease condition therefore deficiency of nephrin had correlated with pathology symptoms of glomerulus injury [5].Some studies using animal subject with diabetic condition suggest that downregula- 

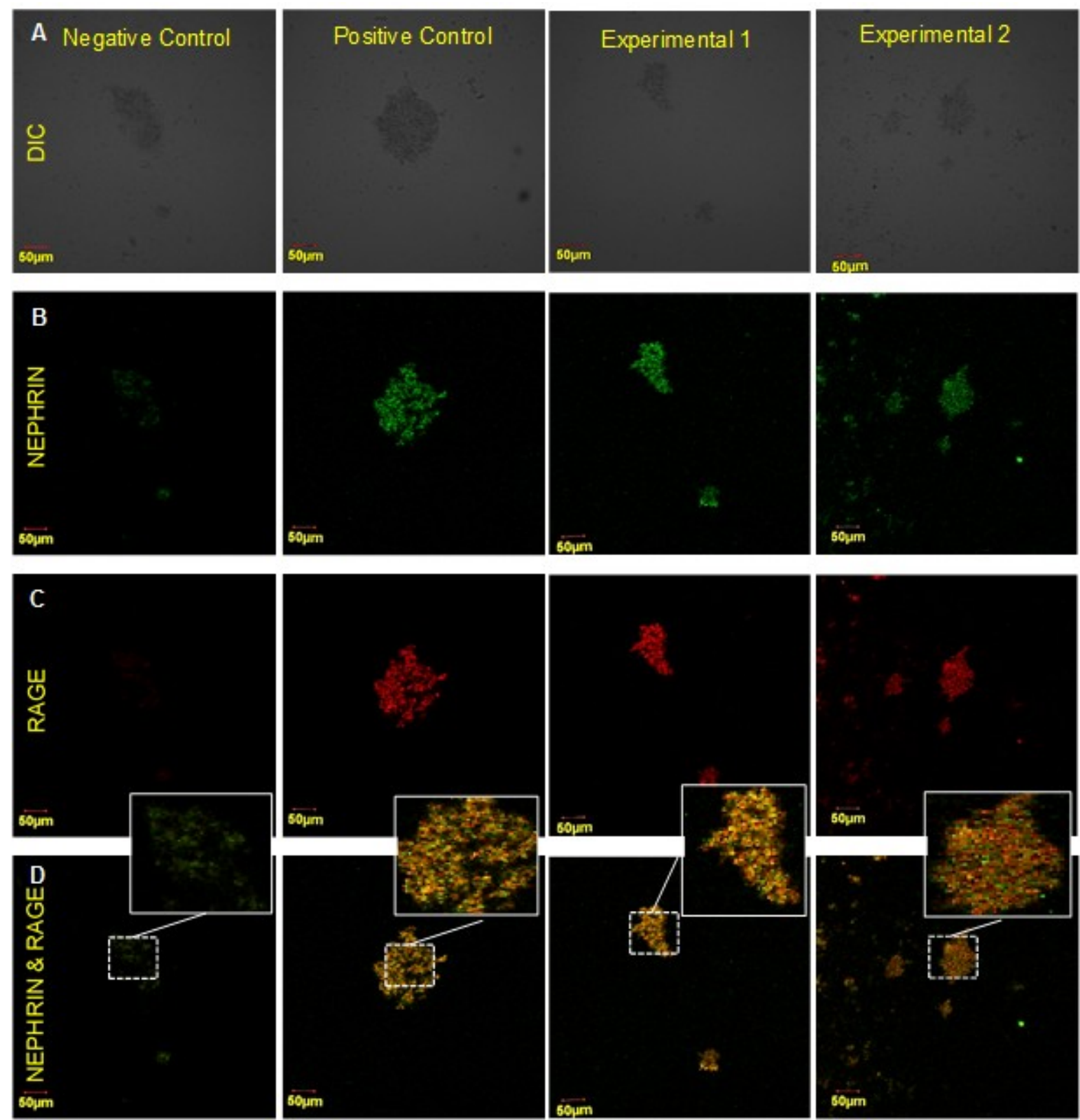

Figure 1. Polyclonal and monoclonal antibody anti-AGE inhibit decreasing of nephrin and downregulation of RAGE in primary culture of glomerulus with AGE than negative and positive control. (A) Representative images of DIC of primary culture of glomerulus in negative control, positive control, experimental group 1 and experimental group 2. (B) Nephrin expression evaluated by immunofluorescence (green). (C) RAGE expression evaluated by immunofluorescence (red). (D) Double immunofluorescence of nephrin and RAGE. Insets, twofold enlargement of boxed area).

tion of mRNA nephrin expression with development of proteinuria in DN [13]. Interestingly, upregulation of nephrin expression has been reported at early stage of glomerular injury and decreased at late stages of nephropathy (follow-up period up to 6 months using STZ model) [1]. In this study, nephrin expression increase in positive control compared with negative control.
Upregulation of nephrin expression in podocytes induced by enhanced angiotensin II activity. Interaction positive control caused by a reaction of podocytes to mechanical stress. Mechanical stress reaction to AGERAGE increases angiotensin II on Renin AngiotensinAldosterone System (RAAS) [3, 14]. Increasing of angiotensin II induced mild to moderate mesangial prolif- 
eration in glomeruli and structural damages in podocytes $[1,3]$. Studies from Wang et al.[6] have proposed that nephrin specific mRNA level was upregulated in PMA (phorbol-12-myristate-13-acetate) groups compared with normal and PKC has determined for the upregulation of nephrin mRNA. This finding support our results of increased nephrin expression in normal primary glomerulus cell which exposed to AGE (positive control).

Administration of monoclonal anti-AGE antibody inhibited increasing of nephrin expression compared to negative and positive control $(\mathrm{p}=0.73 ; 0.125)$. Decreasing of nephrin expression does not differ significantly by administration of polyclonal anti-AGE antibody compared to positive control. Alteration of nephrin expression associated with the activation of PKC. Activation of PKCs are mediated by higher concentrations of ROS then generated following AGE-RAGE interaction [15]. PKCs are divided into three major classes in order of their enzymatic qualities: the conventional PKC/ $c$ PKC $(\alpha, \beta$ I, $\beta$ II and $\gamma$ isoforms) which are activated dependently of calcium and diacylglycerol (DAG), novel $\mathrm{PKC} / \mathrm{nPKC}(\delta, \varepsilon, \eta, \theta$ isoforms) which are activated independently of calcium and dependently of DAG and atypical PKC/ aPKC $(\zeta$, $\mathrm{l}$ isoforms) which are activated independently of calcium and DAG [16]. Upregulation of PKC $\alpha$ which ara activated by DAG and/or calcium lead to enhanced endocytosis of nephrin and instability of the slit diaphragm. Atypical PKC is required for foot process formation, cell polarity and nephrin exocytosis [15]. Hoyer et al. showed that the expression and location of cPKC isozymes $\alpha$ and $\beta$ II were unchanged but atypical PKC isozyme $\zeta$ activity increased up in early diabetes [16]. The results showed that inhibition of AGE using antibody anti-AGE can inhibit interaction of AGE-RAGE and prevent the activation of PKC.

\section{CONCLUSION}

This study suggested that administration of polyclonal anti-AGE or monoclonal anti-CML antibody could inhibit RAGE and nephrin expression in glomerulus primary culture that exposed to AGE.

\section{ACKNOWLEDGMENT}

The authors thank to Nurona Azizah and Musthika Wida Mashitah who have allowed me to joined on Health Professional Education Quality (HPEQ) project and also technical assistance of staffs at Central Laboratory of Life Sciences, especially Helly and Choirunil Chotimah for their excellent laboratory skill guide and advice as well.

\section{REFERENCES}

1. Aaltonen P, Luimula P, Aström E et al. (2001) Changes in the expression of nephrin gene and protein in experimental diabetic nephropathy. Laboratory Investigation 81 (9): 1185-1190.

2. Maezawa Y, Takemoto M, Yokote K (2015) Cell biology of diabetic nephropathy: Roles of endothelial cells, tubulointerstitial cells and podocytes. Journal of Diabetes Investigation 6 (1): 3-15. doi: 10.1111/jdi.12255.

3. Jia J, Ding G, Zhu J et al. (2008) Angiotensin II infusion induces nephrin expression changes and podocyte apoptosis. American Journal of Nephrology 28 (3): 500-507. doi: 10.1159/000113538.

4. Menne J, Meier M, Park JK et al. (2006) Nephrin loss in experimental diabetic nephropathy is prevented by deletion of protein kinase $\mathrm{C}$ alpha signaling in-vivo. Kidney International $70 \quad(8): \quad 1456-1462 . \quad$ doi: 10.1038/sj.ki.5001830.

5. Li X, Chuang PY, D'Agati VD et al. (2015) Nephrin preserves podocyte viability and glomerular structure and function in adult kidneys. Journal of the American Society of Nephrology 26 (10): 2361-2377. doi: 10.1681/ASN.2014 040405.

6. Wang SX, Menè P, Holthofer H (2001) Nephrin mRNA regulation by protein kinase C. Journal of Nephrology 14 (2): 98-103.

7. Goldin A1, Beckman JA, Schmidt AM, Creager MA (2006) Advanced glycation end products: Sparking the development of diabetic vascular injury. Circulation 114 (6): 597-605. doi: 10.1161/CIRCULATIONAHA.106.621854

8. Goh SY, Cooper ME (2008) Clinical review: The role of advanced glycation end products in progression and complications of diabetes. The Journal of Clinical Endocrinology and Metabolism 93 (4): 1143-1152. doi: 10.1210/jc.2007-1817.

9. Reddy S, Bichler J, Wells-Knecht KJ et al. (1995) N epsilon-(carboxymethyl)lysine is a dominant advanced glycation end product (AGE) antigen in tissue proteins. Biochemistry 34 (34): 10872-10878.

10. Müller-Krebs S, Kihm LP, Madhusudhan T et al. (2012) Human RAGE antibody protects against AGE-mediated podocyte dysfunction. Nephrology Dialysis Transplantation 27 (8): 3129-3136. doi: 10.1093/ndt/gfs005.

11. Turk Z, Ljubic S, Turk N, Benko B (2001) Detection of autoantibodies against advanced glycation endproducts and AGE-immune complexes in serum of patients with diabetes mellitus. Clinica Chimica Acta 303 (1-2): 105-115.

12. Win MT, Yamamoto Y, Munesue S et al. (2012) Regulation of RAGE for attenuating progression of diabetic vas- 
cular complications. Experimental Diabetes Research 2012: 894605. doi: 10.1155/2012/894605.

13. Toyoda M, Suzuki D, Umezono T et al. (2004) Expression of human nephrin mRNA in diabetic nephropathy. Nephrology Dialysis Transplantation 19 (2): 380-385.

14. Vidotti D, Casarini DE, Cristovam PC et al. (2004) High glucose concentration stimulates intracellular renin activity and angiotensin II generation in rat mesangial cells. American Journal of Physiology-Renal Physiology 286 (6): F1039-F1045. Doi: 10.1152/ajprenal.00371.2003
15. Teng B, Duong M, Tossidou I et al. (2014) Role of protein kinase $\mathrm{C}$ in podocytes and development of glomerular damage in diabetic nephropathy. Frontiers in Endocrinology 5: 179. doi: 10.3389/fendo.2014.00179.

16. Hoyer DP, Korkmaz Y, Grönke S et al. (2010) Differential expression of protein kinase $\mathrm{C}$ isoforms in coronary arteries of diabetic mice lacking the G-protein G11 $\alpha$. Cardiovascular Diabetology 29 (9): 93. doi: 10.1186/1475-2840-993. 